\title{
EL PRINCIPIO DE RAZONABILIDAD Y LAS EXPECTATIVAS DEL ASEGURADO*
}

\author{
THE PRINCIPLE OF REASONABLENESS \\ AND THE EXPECTATIONS OF THE INSURER
}

\author{
ALONSO NÚNEEZ DEL PRADO SIMONS ${ }^{* *}$ \\ Fecha de recepción: 26 de marzo de 2021 \\ Fecha de aceptación: 15 de abril de 2021 \\ Disponible en línea: 30 de junio de 2021
}

Para citar este artículo/To cite this article

NúÑez del Prado Simons, Alonso. El principio de razonabilidad y las expectativas del asegurado, 54 Rev.Ibero-Latinoam.Seguros, 87-106 (2021).

https://doi.org/10.11144/Javeriana.ris54.prea

doi:10.11144/Javeriana.ris54.prea

\footnotetext{
Este artículo corresponde a la conferencia dictada por el autor en noviembre de 2020 en la sesión del grupo de trabajo del CILA 'Principios generales de Derecho de seguros'. Puede verse en YouTube.

** Abogado, cursó el Magíster en Derecho de la Integración y el de Derecho Constitucional, es Master of Business Administration (MBA) por el College of Insurance (hoy Saint John's University) de Nueva York, graduado en Lingüística y Literatura, además de en Filosofía, en que también cursó el Magíster. Es fundador y Director Ejecutivo del 'Observatorio de cumplimiento de planes de gobierno', profesor universitario, árbitro y conferencista internacional. Es autor de los libros 'Los secretos de los seguros' y 'Derecho de seguros y reaseguro', además de varios otros como coautor. Publica habitualmente en revistas jurídicas y en los principales diarios de Lima. Asimismo, fue Presidente y fundador de la 'Asociación Peruana de Derecho de Seguros', Capítulo de AIDA en el Perú, actualmente es miembro del Consejo de la Presidencia de AIDA mundial y también del CILA y es director de varias entidades del sistema asegurador. https://orcid.org/0000-0002-3482-7423. Contacto: jfalonso@dofnupra.pe
} 


\section{RESUMEN}

El presente artículo luego de exponer los fundamentos de la supervisión del sistema asegurador y los principios del Derecho de seguros, comenta la relación que hay entre el principio de razonabilidad y la doctrina de las expectativas del asegurado del derecho anglosajón que empieza a tener acogida en el Derecho continental. Explica también que pueden entenderse incorporados en el caso peruano por la Ley 29946 del contrato de seguro, vigente desde el mayo de 2013.

Palabras clave: Derecho de seguros, fundamentos de la supervisión, principio de derecho de seguros, principio de razonabilidad, doctrina de las expectativas del asegurado.

\section{ABSTRACT}

This article, after exposing the foundations of the supervision of the insurance system and the principles of insurance law, comments on the relationship between the principle of reasonableness and the doctrine of the expectations of the insured of Anglo-Saxon law that is beginning to be accepted in the Continental law. It also explains that they can be understood to be incorporated in the Peruvian case by Law 29946 of the insurance contract, in force since May 2013.

Keywords: Insurance law, fundamentals of supervision, principle of insurance law, principle of reasonableness, doctrine of the expectations of the insured.

\section{SUMARIO}

1. El derecho de seguros. a. Entre el derecho privado y el público. b. Fundamentos de la supervisión de los seguros. c. Fundamentos de constitucionales de la supervisión. d. Las exclusiones. e. La forma de organización social. f. La función social del seguro. g. Necesidad de una nueva forma de organización social de las empresas de seguros y de su sistema contable. 2. Los principios del Derecho de seguros. a. Los principios incorporados a la ley del contrato de seguro. b. Principios adicionales. c. La participación del corredor. d. La protección de los consumidores y de otros contratantes de seguros. 3. El principio de razonabilidad. 4. El principio de razonabilidad en el Derecho de seguros. 5. La doctrina de las expectativas razonables del asegurado. 6. La doctrina de las expectativas razonables del asegurado. Bibliografía. 


\section{EL DERECHO DE SEGUROS}

El Derecho de seguros es una rama del Derecho cuya clasificación es importante y compleja. Es relevante, porque de ésta resultan muchas consecuencias y es compleja por su origen, ya que fue considerado parte del Derecho Comercial durante mucho tiempo.

Se podría decir que son el conjunto de normas que regulan las operaciones de seguro y la actividad aseguradora en todos sus aspectos y manifestaciones, además de la doctrina y los usos y costumbres que son normas conforme al artículo 2 del Código de Comercio. Asimismo, el Derecho comparado es una herramienta de especial utilidad, porque al fin y al cabo el seguro es un negocio de extensión global al estar involucrado el reaseguro como método de diseminación del riesgo entre los reaseguradores del mundo.

\section{a. Entre el derecho privado y el público}

Hay quien sostiene que parte de las normas que regulan el contrato de seguro pertenecen al Derecho Público, aquellas sobre el control administrativo, y parte al Derecho Privado, aquellas que regulan el contrato de seguro. Sin embargo, incluso el contrato está regulado por una norma de orden público como es la LCS.

En el Derecho de seguros hay ingredientes de Derecho Privado, ya que el contrato de seguro materializado en una póliza es un acuerdo entre dos personas privadas, siendo por lo menos una de ellas una persona jurídica, la aseguradora, porque así lo establece la ley 26702, y tiene que ser una sociedad anónima. Empero también los tiene de Derecho Público, ya que la compañía es una entidad supervisada, porque administra fondos del público asegurado.

Sostener que el contrato es privado es frecuente entre quienes no han profundizado en el tema o prefieren soslayarlo para obtener ventajas y 'olvidan' que el seguro es una mutualidad. El contrato de seguro no puede ser nunca individual, es necesario siempre que sea mutual y un significativo grupo de personas contrate pólizas aportando a un fondo común para que con éste se indemnice a las que tengan ciertas pérdidas, establecidas y detalladas en un contrato (la póliza). Con inusitada frecuencia para defender la libre redacción de los condicionados de las pólizas (en la actualidad en el Perú sólo se comunican a la SBS) se argumenta, a partir del artículo 2, inciso 14, de la Constitución de 1993, vigente, la libre contratación (también en artículo 1354 del Código Civil), pero olvidan su carácter público por disposición constitucional (Art. 87).

El sistema asegurador es una actividad supervisada en el Perú y en todas partes del mundo, porque las compañías, así como los bancos y las AFP, administran fondos del público, en este caso de los asegurados. Como bien lo hizo notar John KaY, en su libro 'Other People's Money' ('El dinero de los demás')1, después de la crisis financiera global, preguntándose si las instituciones del sistema financiero, llamadas

1 Comentado por Eduardo Morón, presidente de APESEG, en su artículo 'La plata de otros', publicado en El Comercio (Portafolio) el 19-02-2016. 
a administrar el dinero de otros2, lo estaban haciendo correctamente. Su respuesta es que no, que el sistema financiero, incluido el de seguros, olvida lo que le conviene al usuario para aumentar sus utilidades. Una de las críticas fundamentales de KaY es que las administraciones de las empresas están preocupadas por la rentabilidad olvidando que sólo administran el dinero de los asegurados, ahorristas, etc. Desde esta crítica cabe preguntarse ¿para quiénes están trabajando estas instituciones?

Hay una pregunta que queda pendiente después de lo que acabamos de exponer y que quizá tenga pronta respuesta en el mundo a pesar de los grandes intereses que afectaría: ¿No sería conveniente que el 'fondo común' que administran las aseguradoras tuviera el carácter independiente e intocable que tiene actualmente en las administradoras de fondos de pensiones?

\section{b. Fundamentos de la supervisión de los seguros}

En opinión de Efrén Ossa el fundamento político legal del control del Estado se impone sobre la actividad aseguradora debido a la importancia que tiene en el ámbito económico financiero de cada país. Reviste varias modalidades según el profesor colombiano. Como veremos, algunas corresponden a su tiempo, pero ya no se aplican más en el nuestro.

- Control técnico. Debe vigilar la determinación y aplicación de tarifas, para que debidamente calculadas, sean adecuadas a las eventuales responsabilidades del asegurador. A partir de la liberalización del mercado de seguros este control ya no se hace. Las tarifas son libres y el resultado de su aplicación puede verse en los estados financieros.

- Control financiero. Que debe proveer la debida evaluación de reservas, pero también a la fidelidad de los estados financieros y su prudente inversión.

- Control jurídico. Dirigido a la preservación de la normativa que rige la actividad aseguradora, pero también en sus relaciones contractuales con los asegurados. Esto ha cambiado y ahora los condicionados son libres, pero deben estar registrados en la SBS, la que no se da tiempo para hacer una verdadera auditoría de los textos, además de que no tiene a su equipo con la preparación suficiente para hacerlo

- Control contable. Velar por la más estricta fidelidad de las cuentas de la empresa.

- Control político económico. Era un control encauzado a proteger el seguro nacional contra el seguro extranjero y proveer el seguro estatal. También desapareció con la liberalización del mercado. En la actualidad cada aseguradora busca su propio reaseguro, aunque todavía no funcionan oficialmente las aseguradoras no registradas como en otros países.

\footnotetext{
2 Gianfranco Ferrari, Gerente General del Banco de Crédito, el más grande e importante del Perú, reconoce: "recordemos, 9 de cada 10 soles que prestan las instituciones financieras son de los depositantes" en un artículo publicado en el diario El Comercio el 6 de agosto de 2020 titulado 'Ceviches, cortes de pelo y taxis gratis'.
} 
Las compañías de seguros no solamente son supervisadas durante su constitución, sino que también a lo largo de toda su vida jurídica, incluida su eventual liquidación, porque administran fondos del público (intereses y derechos de los asegurados). Según Efrén Ossa el Estado tiene como objetivo la preservación de la estabilidad de los seguros como engranaje al servicio de la comunidad asegurada y el orden social.

\section{c. Fundamentos de constitucionales de la supervisión}

Lo expuesto en el punto anterior explica y justifica la supervisión del sistema de seguros por la Superintendencia de Banca, Seguros y AFP que está establecida en nuestra Carta Constitucional (Art. 87), ya que como he indicado anteriormente el dinero con que se pagan las pérdidas o siniestros de los miembros que aportan a una determinada bolsa común es en realidad de todos ellos y la compañía de seguros sólo lo administra. Al final, es la misma razón por la que la misma entidad supervisa la operación de los bancos, financieras y administradoras de fondos de pensiones (AFP) que también administran fondos del público que en ese caso son los ahorros y similares y sirven para financiar a los clientes que lo requieran o para pagar las pensiones de quienes se jubilen ${ }^{3}$.

El problema es que el primer párrafo del artículo $87^{\circ}$ de la Constitución está redactado usando la palabra 'ahorros' que hace alusión a los bancos y AFP y no a los seguros. Quizá sería mejor reemplazarla por 'fondos del público', por lo menos en la segunda frase. El segundo párrafo aclara la confusión cuando dice 'de las demás que reciben depósitos del público', aunque en estricto las primas no lo son. También en este caso convendría cambiar 'que reciben fondos del público', por 'administran fondos del público'. El texto vigente a la letra dice:

Art. $87^{\circ}$. El Estado fomenta y garantiza el ahorro. La ley establece las obligaciones y los límites de las empresas que reciben ahorros del público, así como el modo y los alcances de dicha garantía.

La Superintendencia de Banca, Seguros y AFP ejerce el control de las empresas bancarias, de seguros, de administración de fondos de pensiones, de las demás que reciben depósitos del público y de aquellas otras que, por realizar operaciones conexas o similares, determine la ley.

La ley establece la organización y la autonomía funcional de la Superintendencia de Banca, Seguros y AFP.

El Poder Ejecutivo designa al Superintendente de Banca, Seguros y AFP por el plazo correspondiente a su período constitucional. El Congreso lo ratifica.

Esta supervisión que puede incomodar a las empresas supervisadas es necesaria para salvaguardar el riesgo de eventuales malos manejos e incluso que se tomen excesivos

\footnotetext{
3 El conocido penalista César AzABaChe C. en un artículo periodístico ('Falso Mecenazgo y fidelización') afirmó que "Las corporaciones, especialmente las financieras, ... Son creadas para sostener y desarrollar los ahorros del público, que es un colectivo concreto poblado de intereses y preferencias disímiles. El público entrega a los ejecutivos de una corporación financiera un amplio margen de discreción regulada para que cumplan su misión.” (El Comercio, 25/11/2019, p. 34).
} 
riesgos en su administración. Tampoco es que sea patrimonio de nuestro país, ya que la supervisión de todas esas operaciones se da en todas partes del mundo y es producto de la experiencia. Muchas veces, como vimos recientemente en la crisis financiera del 2008, se ha burlado el control o éste se ha hecho muy laxo, de tal manera que el público ha resultado perdiendo su dinero. Sorprendentemente, podemos encontrar personas que sostienen que esa crisis fue producto del exceso de regulación. Son los que pretenden convertir al mercado en un dios capaz de solucionarlo todo.

A partir de lo antes expuesto es que tenemos que delimitar las capacidades de las aseguradoras y su forma de funcionamiento que ha sido deformado por la estructura legal en que ha devenido su organización. La mayor parte de las aseguradoras y muchas de las que en la actualidad son de las más importantes (por ejemplo, Prudential, Metropolitan, etc.) en los Estados Unidos empezaron y se desarrollaron como mutuales, pero con el tiempo algunas se han convertido en sociedades por acciones que como todos sabemos buscan maximizar el lucro en vez de servir los intereses de los asegurados, verdaderos propietarios de los grandes capitales que administran.

En un reciente Congreso del Comité Ibero-Latinoamericano de AIDA (Association Internationale de Droit des Assurances) un profesor sostuvo que el dinero con que las compañías de seguro pagaban los siniestros era de su propiedad. Le dije que el hecho de que estén organizadas como sociedades por acciones sólo creaba una ficción jurídica, pero que no le quitaba verdad a que el dinero con que se pagaban las pérdidas proviniera de las primas de todos los que aportaban al fondo (que ingresa a la contabilidad de la aseguradora y por tanto es de su 'propiedad'). Conviene aquí recordar un viejo refrán que dice: "aunque a la mona se la vista de seda, mona se queda". Puede decirse que el fondo con que se pagan los siniestros es de 'propiedad' de la compañía, pero todos sabemos de dónde proviene. El principio de primacía de la realidad.

\section{d. Las exclusiones}

La historia de los seguros es la historia de las exclusiones. Cada vez que se tiene un gran siniestro o alguno que las aseguradoras prefieren no cubrir, lo excluyen. ¿No sería mejor que tengamos condicionados mínimos y que la competencia se dé hacia arriba? Eso propusimos hacer con la nueva LCS, pero la SBS se opuso y no fue posible.

\section{e. La forma de organización social}

La forma de organización social, sociedades anónimas, ha creado una ficción jurídica que distorsiona la realidad sobre todo en los países en que no han existido aseguradoras mutuales. Creo que deberíamos pensar en una nueva forma de organización social.

\section{f. La función social del seguro}

El sistema asegurador cumple una muy importante función social que en ningún caso puede olvidarse, más aún si tenemos presente que los fondos que administra son del público (los asegurados). En efecto, las aseguradoras no pueden olvidar esa función en 
el desarrollo de sus labores, por lo que todo su esfuerzo debe siempre estar enfocado en esa primordial labor que realizan en la sociedad en la que trabajan, subordinando sus otros objetivos empresariales, como el ánimo de lucro, a ese fin. Por eso es me atrevo a sugerir que la organización social de las empresas de seguros sea modificada y se adecúe a la sugerencia de Klaus SchWAB que desarrollo más adelante.

En situaciones límite, como la que vivimos con el COVID-19, las compañías de seguros tienen que actuar teniendo muy presente su importante función social, tratando de colaborar para que el sistema de salud y especialmente el económico no colapse a pesar de que esto afecte seriamente sus utilidades. Al final, se deben a la sociedad en que desarrollan sus actividades y en especial a sus asegurados (personas naturales y jurídicas) cuyos fondos administran.

\section{g. Necesidad de una nueva forma de organización social de las empresas de seguros y de su sistema contable}

Considero que nuestra legislación, especialmente en la referente a la organización social de las compañías de seguro debería acoger la propuesta de Klaus Schwab fundador del Foro Económico Mundial, y que intervino En el último CADE de 2020, quien desde hace medio siglo pretende reemplazar el capitalismo de accionistas por el capitalismo de valor compartido, en el que las empresas ya no sólo se deberían a sus accionistas, sino a la sociedad entendida como sus proveedores, clientes, comunidad, gobierno y ecosistema. Como hizo notar Diego Macera ${ }^{5}$, la Business Roundtable (BRT), una especie de CONFIEP para gerentes generales de los Estados Unidos -a quienes no se puede considerar como anticapitalistas o antisistema-, redefinió el propósito de una empresa, poniendo los intereses de la sociedad al nivel de los intereses de los accionistas que al final son parte de la primera.

El hecho de que el fondo que administran las aseguradoras sea en realidad propiedad de los asegurados, como he venido insistiendo, hace de especial conveniencia acogerse a esta propuesta que, probablemente, sea beneficiosa para todas las sociedades mercantiles. Podríamos empezar con las compañías de seguros. Sin embargo, me queda claro que esto no es solo materia de una modificación legislativa, sino que hace necesario un cambio cultural que hay que trabajar desde todos los sectores.

A partir de la experiencia de las AFP, que fueron organizadas contablemente separando el fondo que administran del capital y patrimonio de la empresa, considero conveniente replicar el modelo en las aseguradoras de tal manera que el 'fondo común' resultado del pago de las primas de seguros del que se pagan los siniestros sea independiente e intocable. Así quedaría claro que las empresas sólo administran este fondo. Habría que definir una forma de pago a las compañías por este trabajo, pero que debería estar vinculado a la calidad de la administración y la rentabilidad que obtengan.

\footnotetext{
En su artículo ‘¿Qué tipo de capitalismo queremos?' publicado en Project Syndicate. The World's Opinión Page el 2 de diciembre de 2019. https://www.project-syndicate.org/commentary/stakeholdercapitalism-new-metrics-by-klaus-schwab-2019-11/spanish

5 Artículo en el diario El Comercio del 30 de enero de 2020
} 
Ambas propuestas son ambiciosas y rompen con el statu quo actual, pero por lo menos deberíamos debatirlas, aunque me temo que serán tildadas de locura por todos los intereses que están detrás. Pero como decía Hegel las ideas penetran lo que me anima a proponerlas a pesar del rechazo de que serán objeto.

\section{LOS PRINCIPIOS DEL DERECHO DE SEGUROS}

\section{a. Los principios incorporados a la ley del contrato de seguro}

Los principios pueden ser diferentes dependiendo de quien los proponga. En los 80's tuve acceso a un curso londinense que consideraba sólo cuatro:

- Indemnización

- Subrogación

- Contribución

- Máxima buena fe

- Interés asegurable

- Doctrina de la causa próxima (adecuada)

Fue idea mía incorporar los principios mencionados a la ley del contrato de seguro (29946) en el Perú, pero agregué el principio de mutualidad, por razones muy concretas: las aseguradoras que hasta antes de la liberalización del mercado en 1991 cubrían las preexistencias dejaron de hacerlo y las excluían incluso si el asegurado cambiaba de producto en la propia aseguradora. Además, hacían recargos individuales en seguros médicos. Por insistencia de algunos de los otros miembros de la comisión que redactamos el Proyecto, se incorporó incluso uno adicional: la interpretación contra proferentem o contra stipulatorem, que en mi opinión fue una redundancia, porque ya estaba establecida en los criterios de interpretación, que también se incorporaron a mi iniciativa. Yo los había tomado del proyecto que preparó el profesor Juan Carlos FÉLIX MoRANDI. En realidad, casi todo el título I, una especie de título preliminar fue de mi autoría.

La presencia de principios en nuestra ley ha sido de mucha utilidad, en la resolución de casos, muy especialmente el de mutualidad y el de buena fe. Ambos sin duda parte del Derecho de seguros, pero que resulta conveniente tenerlos incorporados en la propia legislación.

\section{b. Principios adicionales}

Recientemente, recibí el libro que editaron Kyriaki Noussia y Pierpaolo Marano sobre Transparencia ${ }^{6}$, (en el que participé con el artículo sobre Perú), tema que ya se

\footnotetext{
6 Marano, Pierpaolo y Noussia, Kyriaki, editores. Transparency in Insurance Law. Springer. Cham, Suiza, 2019.
} 
había tratado en varios congresos internacionales, y considero importante incluir el principio de transparencia, aunque en mi percepción es parte del de buena fe.

Al escribir un artículo para la publicación de la PUCP titulada 'Derecho de los desastres' me encontré con la necesidad de incorporar expresamente dos adicionales: el principio de razonabilidad y la doctrina de las expectativas razonables, que, en mi opinión también deben ser parte del de buena fe, ya que de éste se derivan.

Es conveniente hacer notar que ya en España lo han comentado con amplitud J. A. BALLESTEROS GARRIDO y nuestra ley del contrato de seguro (LCS) lo permitía. Afirmo esto último, porque la LCS incorpora reiterada y expresamente el principio de razonabilidad y por ende el de expectativas razonables. En la ley 29946 del contrato de seguros de Perú, la palabra razonable aparece cinco veces (artículos IV, décima, 69, 92, 93 y 106). Sin embargo, creo que nos convendría incluirlos expresamente. Con posterioridad, también descubrí que en Chile se había escrito y comentado (Iñigo DE LA MAZA y Ruperto PINOCHET) favorablemente, sobre la doctrina de las expectativas razonables.

\section{c. La participación del corredor}

¿La participación del bróker consigue que el contrato de seguro deje de ser por adhesión? Nuestra LCS dice que no y que hay que ver cada póliza.

\section{d. La protección de los consumidores y de otros contratantes de seguros}

¿Sólo deberíamos proteger a los ‘consumidores’? ¿Dónde quedan la mayoría de las empresas que contratan pólizas a las que no consiguen modificar nada importante, aunque intervenga el más profesional de los brókeres? ¿Es tan competitivo el mercado que hay aseguradoras dispuestas a conceder lo que el cliente requiere? En mi experiencia, los únicos que consiguen modificar de manera importante los textos de sus condiciones son los grandes riesgos, pero no los que considera grandes riesgos la legislación chilena (pólizas con primas de US\$ 7,200.00), que además las excluye de la protección de la ley quedando a disposición del texto redactado por las aseguradoras. Tampoco de lo que considera 'grandes riesgos' la legislación europea, que los define convencionalmente con cifras que incluyen a lo que llamaríamos 'riesgos medianos'. Claro que en este caso el resultado es muy diferente: las partes (asegurado y asegurador) pueden escoger la ley y la jurisdicción a la que se someten. En el Perú, un gran riesgo es una empresa que paga por lo menos 5 millones de dólares en primas y no lo es en todas sus pólizas, ya que hay muchas en que no consigue modificar ni una coma. Por eso es que considero que la mejor definición de un gran riesgo es 'una empresa que consigue importantes cambios en sus pólizas contra lo pre-redactado por la aseguradora'. Y es también por esa razón que nuestra LCS (Art. 3) remite a una decisión de caso por caso, la consideración de gran riesgo y la no aplicación de la interpretación contra proferentem. 


\section{EL PRINCIPIO DE RAZONABILIDAD}

Según el diccionario de la Real Academia de la Lengua (DRAE), racionabilidad es la facultad intelectiva que juzga de las cosas con razón, discerniendo lo bueno de lo malo y lo verdadero de lo falso. Su origen etimológico se encuentra en el vocablo latino rationabilĭtas, -ātis. Se refiere a lo que resulta razonable y que, en consecuencia, es conforme a la razón. En el mismo diccionario la palabra razón tiene un largo número de acepciones, pero para nuestro caso podríamos decir que es la capacidad que tenemos los seres humanos de reflexionar y analizar en búsqueda de una conclusión. A este proceso se le llama razonamiento ${ }^{7}$.

Annarita RicCI, quién con motivo de su estudio en torno a la razonabilidad en el Derecho privado, recuerda que, "En las cláusulas generales se materializa la máxima forma de apertura del sistema jurídico en relación con juicios de valor no codificados pero representativos de intereses reconocidos de la sociedad civil..."8 Aunque refiriéndose a la responsabilidad civil, pero aplicable al tema que tratamos, Carlos Ignacio JARAMILlo dice: “ ... hacen parte del 'juicio de responsabilidad' que, de ordinario, realiza el juez, ese que debe ser sensato, equilibrado y balanceado, criterioso, ecuánime, adecuado, en fin, en un solo término arropador: razonable".

En el ámbito contractual es el criterio que regula el ejercicio de los derechos de las partes. En el derecho laboral se emplea para impedir que tanto los empleadores como los trabajadores abusen de los derechos que la ley les reconoce. Se podría decir que el principio de razonabilidad pretende el imperio de la lógica y del sentido común. Cuando se celebra un contrato, las partes se comprometen a cumplir diversas obligaciones y a respetar ciertos derechos y se dice que en esta relación debe haber proporcionalidad y razonabilidad. Aparte del principio de razonabilidad, existen formas jurídicas que tienen por objeto garantizar a las personas un trato justo por parte de quienes tienen algún poder sobre ellos. Por eso es que tiene gran uso y vigencia en el Derecho constitucional y en el laboral.

En ciertas circunstancias el principio de proporcionalidad resulta análogo al de razonabilidad, porque pretende evitar que una persona abuse de su poder para sancionar a otra y privarla de su libertad, por lo que busca que su uso esté limitado a la protección de bienes jurídicos de gran valor.

No obstante, conviene recordar que la razonabilidad es relativa, no sólo en el ámbito personal e informal, sino también jurídicamente. Resulta difícil dar una respuesta definitiva a la pregunta: ¿qué es razonable?, porque por lo general eso depende de cada caso específico. Resulta entonces conveniente que el principio de razonabilidad vaya evolucionando con el tiempo y adecuándose a cada caso, evitando así rigideces que pueden momificarlo.

\footnotetext{
7 “En relación más directa con la temática de la razonabilidad como ‘cláusula general', o como 'concepto jurídico indeterminado', entre otras denominaciones y expresiones, véase a TroiAno, Stefano. $L a$ ragionevolezza nel diritto dei contratti, Cedam, Padova, 2005, pp. 47 y ss.

8 "Il criterio della ragionevolezza nel diritto privato, Le monografie di Contratto e Impresa", Cedam, 2007, p. 149. Citada por: Jaramillo, Carlos Ignacio y Kemelmajer de Carlucci, Aída. El criterio de razonabilidad. Editorial Ibáñez. Bogotá, 2020
} 
Creo que podemos decir que lo razonable es lo que puede justificarse, que no es arbitrario, en especial cuando está de por medio el principio de igualdad. También que tiene relación con la proporcionalidad con el equilibrio y la necesidad de armonía.

En el plano internacional conviene hacer notar que los principales instrumentos de unificación y armonización del derecho privado como son: la Convención de Viena sobre Compraventa Internacional de Mercaderías (CISG), los Principios Unidroit o Principios Europeos de Derecho de los Contratos (PECL), el borrador de Marco Común de Referencia (DCFR) y los recientes Principios Latinoamericanos de Derecho de los Contratos (PLDC), tienen como característica la amplia presencia de la noción de razonabilidad.

\section{EL PRINCIPIO DE RAZONABILIDAD EN EL DERECHO DE SEGUROS}

De lo expuesto, podemos concluir que el principio de razonabilidad es perfectamente aplicable al Derecho de seguros, es más, dadas las características de este último, es necesario. En el caso peruano, es aún de más fácil aplicación, porque el principio de buena fe está expresamente incorporado en la LCS (Art. II, a). Creo que es bastante obvio que hay una relación muy grande entre ambos principios y que contractualmente la razonabilidad se desprende de la buena fe.

Así como se espera un comportamiento razonable del asegurado, antes y durante la vigencia del contrato de seguro, además de cuando ocurre un siniestro, corresponde también a la contraparte (aseguradora) proceder de la misma manera. Considero que, en este último caso, es de especial importancia la conducta de la compañía en la etapa previa a la celebración del contrato de seguro; y esta es la redacción del condicionado y las cláusulas adicionales que pueden incorporarse. Por lo tanto, podemos concluir que el texto de las condiciones generales y especiales de cualquier póliza de seguro tiene que ser razonable y los excesos y abusos no son válidos, en especial en las exclusiones, pero también en otros aspectos como las caducidades y limitaciones a los derechos del asegurado.

Una lectura sistemática e integradora de la LCS nos llevará a la evidente conclusión que está impregnada del principio de razonabilidad, aunque creo que no estaría demás que se le incorporará de forma expresa.

Veamos con detalle. Ya el artículo I (Título I, Disposiciones Generales) que indica el carácter imperativo de la norma, termina diciendo: "No obstante, en caso de conflicto son de aplicación las normas más favorables al consumidor o usuario". Luego el artículo II que señala los principios que rigen el contrato de seguro incluye expresamente la buena fe (a), la mutualidad (c) y la interpretación contra proferentem (f). A continuación, el artículo III establece que el contrato de seguro se celebra por adhesión, dejando la carga de la prueba del lado de la aseguradora. Más adelante, el artículo IV, referente a la interpretación, en su tercera regla reitera la interpretación contra stipulatorem; la novena dice: "Las cláusulas que imponen la caducidad de 
derechos del contratante, asegurado o beneficiario, deben ser de interpretación restrictiva en su alcance y en los hechos que tienden a acreditar su procedencia. Su redacción debe ser clara, simple y precisa". La Décima establece el principio de razonabilidad de manera expresa: "Las cargas impuestas convencionalmente al contratante, asegurado o beneficiario, deben ser razonables". La Decimoprimera, también va por el mismo camino: "Para determinar la observancia de cláusulas de garantía, prescripciones de seguridad o medidas de prevención, debe tenerse en cuenta más el cumplimiento sustancial de las mismas y su eficacia efectiva, que su cumplimiento literal. No se debe sancionar al asegurado por incumplimiento de garantías o medidas cuya observancia no hubiera evitado el siniestro". Asimismo, la Decimosegunda. "Son nulas aquellas estipulaciones contractuales que amplían los derechos del asegurador o restringen los del asegurado en contravención de las disposiciones establecidas en la presente ley". Todo esto consta de la especie de título preliminar que es el Título I (Disposiciones generales) de la LCS.

Ya en el Título II, referente al contrato de seguro mismo, la LCS hizo una modificación muy importante, a pesar de la abierta oposición de las compañías, y en su artículo 21 redujo de manera importante la suspensión de cobertura por mora en el pago de la prima9 obligando a las aseguradoras a comunicar de manera cierta al tomador o asegurado de su atraso y luego esperar un plazo de 30 días para que entre en efecto.

a) Reitera el principio de razonabilidad lo fijado en la parte final del artículo 26 (Contenido de la póliza) donde se dispone:

Las condiciones generales, particulares y, las especiales que sean aplicables al contrato, deben cumplir con los siguientes requisitos:

Concreción, claridad y sencillez en la redacción con posibilidad de comprensión directa, sin reenvíos a cláusulas y pactos no contenidos en la póliza.

Estar ajustadas a la buena fe y justo equilibrio entre los derechos de las partes.

b) El artículo 28 obliga a que las cláusulas que consagran caducidades a los derechos del asegurado, suspensiones o exclusiones de cobertura se consignen en caracteres notorios, así como las cláusulas de garantía que tendrán que constar además en la parte frontal de la póliza. El artículo 29 decreta que en caso de que de diferencia entre la propuesta y la póliza prevalece la más favorable para el asegurado, salvo que la compañía lo haya advertido expresamente en documento adicional a la póliza dándole 30 días para rechazarla. De forma similar, el artículo 31 señala la prevalencia de lo más favorable para el asegurado en caso de diferencia entre la publicidad y la póliza.

c) Los artículos 39, 40 y 41 de la LCS referidos a cláusulas, estipulaciones y prácticas abusivas son muy amplios e instauran como abusivas, por ejemplo, "todas aquellas estipulaciones no negociadas que, aun cuando no hayan sido observadas por la Superintendencia, causen en contra de las exigencias de la máxima buena fe, en perjuicio del asegurado, un desequilibrio importante de

\footnotetext{
9 Hasta que la LCS entró en vigencia la suspensión de cobertura por mora en el pago de la prima era automática y el asegurado se quedaba sin ésta al día siguiente de que dejara de pagar una cuota de su seguro.
} 
los derechos y obligaciones de las partes que se deriven del contrato" $(39, \mathrm{I})$; "el hecho de que ciertos elementos de una cláusula o que una cláusula aislada se haya negociado no excluirá la aplicación del presente artículo al resto del contrato, si la apreciación global lleva a la conclusión de que se trata, no obstante, de un contrato por adhesión" (39, II); "el carácter abusivo de una cláusula se apreciará teniendo en cuenta, además de la situación ventajosa que se genere para el asegurador en perjuicio del asegurado, la naturaleza de los bienes o servicios materia del contrato y de su celebración, así como el resto de cláusulas del contrato" $(39$, III); "el carácter abusivo de una cláusula subsiste aun cuando el contratante y/o asegurado la haya aprobado específicamente por escrito" (39, IV); las estipulaciones "que dispongan la pérdida de derechos del asegurado y/o beneficiario por incumplimiento de cargas que no guardan consistencia ni proporcionalidad con el siniestro cuya indemnización se solicita" $(40$, d); .las "que establecen la caducidad o pérdida de derechos del asegurado en caso de incumplimiento de cargas excesivamente difíciles o imposibles de ser ejecutadas" $(40, \mathrm{f})$, "las que imponen la pérdida de derechos del asegurado en caso de violación de leyes, normas o reglamentos, a menos que esta violación corresponda a un delito o constituya la causa del siniestro" $(40, \mathrm{~g})$. Dentro de las prácticas prohibidas aparece "desconocer o restringir el derecho del asegurado a contar con el asesoramiento en la contratación de seguros y/o servicios de gerencia de riesgos y/o siniestros de parte de un corredor de seguros autorizado". La LCS instaura un proceso sumarísimo (el más breve que permite nuestro derecho procesal) para los reclamos por prácticas abusivas (Art. 42).

d) Por otro lado, subsiste la cobertura si el asegurado o beneficiario si prueban su falta de culpa en caso de incumplimientos o que medió caso fortuito, fuerza mayor o imposibilidad de hecho (Art. 71) siguiendo lo establecido en el artículo 1314 de nuestro Código civil. Asimismo, la informalidad (un fenómeno generalizado en el Perú10) no puede ser argumento para rechazar un siniestro (Art. 84). En caso de salvamento y de órdenes contradictorias de dos aseguradores, el asegurado debe decidir cuáles le parecen más razonables (Art. 92). También se indica que el asegurador debe reembolsar los gastos razonables incurridos para el salvamento (Art. 93). También en los seguros de responsabilidad civil el asegurado debe cooperar en la defensa judicial 'en la medida de la razonabilidad de sus posibilidades (Art. 106).

e) Otras disposiciones de la LCS favorables a la razonabilidad del contrato son la obligación en seguros médicos de cubrir las enfermedades preexistencias cuando se ha tenido seguro anterior (Art. 118); la incontestabilidad a los dos años en los seguros de vida (Art. 122), que es generalizada en la mayor parte del mundo, y el establecimiento de la proporcionalidad de la prestación del asegurador en el caso de declaración inexacta de la edad, salvo que exceda los límites establecidos para la póliza en los que sólo se devolverá la prima (Art. 123).

f) Después de lo expuesto podemos decir que, como corresponde a la equidad exigida por el Derecho, en el caso de una controversia, la compañía de seguros tendrá la posibilidad de defender la razonabilidad del texto de las condiciones y cláusulas que redactó, haciendo notar los casos específicos en

10 La economía peruana es casi $70 \%$ informal según cifras aceptadas mayoritariamente. 
que han tenido cambios importantes a pedido del asegurado. Esta eventual explicación podría tener necesidad de sustento técnico, de las costumbres de la industria y del Derecho comparado.

g) Esta razonabilidad también obliga al supervisor, que deberá tener mucho cuidado controlando los cambios que las aseguradoras vayan realizando en el texto de sus pólizas, ya que, lamentablemente, la historia nos muestra que las exclusiones han ido en incremento a través de los años. Ha sido la forma en que la industria ha protegido su rentabilidad, pero ha olvidado que al final es mera administradora de los fondos de los asegurados y en consecuencia se debe a ellos. Sus intereses tienen que estar subordinados a los superiores de los asegurados.

\section{LA DOCTRINA DE LAS EXPECTATIVAS RAZONABLES DEL ASEGURADO}

Como respuesta a lo expuesto, una de las doctrinas que surgió en el Derecho de seguros en los últimos treinta años es la de las expectativas razonables.11 Es un principio que se basa en las 'expectativas razonables del asegurado' como guía para la interpretación ${ }^{12}$ del contrato de seguro. Según esta doctrina, los tribunales otorgan cobertura a un asegurado incluso cuando el condicionado expreso de la póliza la niega.

La doctrina de las expectativas razonables va más allá de contra proferentem, la regla tradicional de interpretación ${ }^{13}$, a la que algunos interesados han pretendido confinarla. Contra proferentem -también conocida como contra stipulatorem- otorga cobertura a un asegurado mediante la construcción de un texto de póliza ambiguo, contra la compañía de seguros. En contraste, la doctrina de las expectativas razonables otorga cobertura cuando el asegurado tiene una expectativa razonable de cobertura incluso en ausencia de un texto ambiguo en la póliza de seguro.

En la jurisprudencia estadounidense han surgido diferentes enfoques de la doctrina, pero los más fuertes, ignoran el texto claro del contrato de seguro y honran las expectativas razonables del asegurado. Como era de esperar, esto no ha sido del agrado de las aseguradoras que están contraatacando y sostienen que hay mucha controversia, además de pretender reducir su aplicación a solo los casos de textos ambiguos, cuando en realidad, como su propio nombre lo indica, va mucho más lejos. No tiene mayor sentido que esta doctrina duplique un canon tradicional de interpretación. No obstante, los ataques y la enorme influencia del sector asegurador, ha llevado a que exista jurisprudencia contradictoria en las diversas jurisdicciones de los Estados Unidos e incluso dentro de algunos de las que la han adoptado ${ }^{14}$. Estamos entonces en un proceso en el que se discute si, efectivamente, una jurisdicción ha adoptado

\footnotetext{
11 RAHDERT, Mark C. Reasonable Expectations Revisited, 5 CONN. INS. L.J. 107, 108 (1998).

12 Ibidem (citando a Robert E. KeEton, Insurance Law Rights at Variance with Policy Provisions, 83 HARV. L. REV. 961,970 n.14 (1970)).

13 Anderson, Eugene R. \& Fournier, James J. Why Courts Enforce Insurance Policyholders' Objectively Reasonable Expectations of Insurance Coverage, 5 CONN. INS. LJ. 335,342-45 (1998).

14 Henderson, Roger C. The Doctrine of Reasonable Expectations in Insurance Law After Two Decades, 51 OHIO ST. LJ. 823,824 (1990).
} 
la doctrina y el enfoque que le ha dado, aunque me atrevo a predecir que ya no hay camino de regreso a pesar de todos los esfuerzos y el poder del sistema asegurador.

Para Carlos Ballugera, "La enorme influencia en España -y por ese camino en Latinoamérica- de las doctrinas alemanas sobre las condiciones generales de la contratación no puede llevar a olvidar aproximaciones como ésta a los problemas del moderno Derecho contractual"15.

En opinión de J. A. Ballesteros, uno de los aspectos llamativos de la doctrina jurisprudencial de las expectativas razonables del asegurado es la pérdida de sentido de la firma como declaración de voluntad, de la "parol evidence rule" en los contratos por adhesión16. Para BALlesteros, el comercio a gran escala y la firma automática por los consumidores de los contratos pre-redactados, llevan a la conclusión de que la firma no puede entenderse como consentimiento, de manera que, por ejemplo, la póliza de seguro, ya no es la única fuente de contenido contractual. Los clausulados de gran tamaño, pero de difícil comprensión, lleva a que, aunque los lean, no es probable que los entiendan y no puede entenderse consentido aquello que no se conoció o que no pudo comprenderse. A esto habría que agregar, como ya he indicado, que las posibilidades de modificarlos son casi nulas, por lo que tampoco serviría de mucho leerlas e incluso comprenderlas ${ }^{17}$.

Los contratos son inviolables y en principio el Estado no puede controlarlos, pero en ciertos casos es demasiado optimista sostener que el consentimiento libre de las partes es la mejor garantía de equilibrio y justicia, No obstante, esto ha sido limitado grandemente por las normas de protección al consumidor, debido a la multiplicación de los contratos por adhesión, que tiene sustento en el artículo 62 de nuestra Carta Magna. Por otro lado, el caso de los seguros y del sistema financiero en general son por cierto diferentes al ser regímenes supervisados conforme al artículo 87 del texto constitucional y tener importantes ingredientes de Derecho público, justamente porque las aseguradoras administran dinero de los asegurados y ahorristas. Pero para los demás casos salvo la exclusión de la rescisión por lesión, hay una especie de presunción "iuris et de iure" de que el contrato libremente consentido es equilibrado, como lo afirma el neoliberalismo economicista, tan de moda en nuestros tiempos, porque piensan que el interés individual y el egoísmo constituyen la mejor garantía.

La realidad de nuestros tiempos ha revelado que, en los contratos por adhesión, el comprador está sometido a los términos pre-redactados por el vendedor masivo y usualmente firma sin objeciones el supuesto contrato que de lo último que tiene es de acuerdo de voluntades. Lo expuesto ha llevado a la necesidad de cambiar radicalmente muchos de los supuestos del derecho contractual respecto a los contratos por adhesión. Es probable que, por lo menos en seguros, sea necesaria la elaboración de pólizas

\footnotetext{
15 BALlugera Gómez, Carlos. Las expectativas racionales del adherente y los tratos preliminares a los 20 años de la ley de condiciones generales. En: https:/enlacancha.eu/2018/01/11/las-expectativas-racionalesdel-adherente-y-los-tratos-preliminares-a-los-20-anos-de-la-ley-de-condiciones-generales/

16 Ballesteros Garrido, J. A. Las condiciones generales de los contratos y el principio de autonomía de la voluntad, José María Bosch Editor, Barcelona, 1999

17 Ibidem.
} 
con condicionados mínimos que permitan establecer un piso (que se iría elevando con el tiempo) de tal manera que la competencia se dé hacia arriba y no a costa de los más débiles para que las compañías tengan mayores utilidades. A estas alturas, resulta necesario reconocer que el control de los contratos por adhesión mediante la posibilidad de considerar abusivas algunas de sus cláusulas o mediante el uso de la interpretación sistemática y contra proferentem no ha sido suficiente y que los abusos crecen con el único objeto de incrementar las utilidades.

Para BALlugera las teorías normativistas han resultado insatisfactorias, ya que se detienen en el hecho sociológico de la vigencia de las condiciones generales, olvidando que el Derecho no debe detenerse ante los hechos y aceptarlos, sino que debe dar categoría de jurídico solamente a lo justo, descartando lo demás. En consecuencia, no se puede atribuir valor normativo al contrato por adhesión, sino que es necesario ponerle límites, como el de dejar de considerar la sola firma como una manifestación de voluntad. Agrega que las tesis contractualistas son en el fondo contradictorias porque consideran que la adhesión al contrato es consentimiento, las condiciones generales son parte del contrato y obligan, y por otro lado aceptan los controles formales y de contenido en los contratos por adhesión, que se fundan en la falta de libertad del adherente. En otras palabras, afirman al mismo tiempo la libertad y la falta de libertad del adherente ${ }^{18}$.

\section{LA DOCTRINA DE LAS EXPECTATIVAS RAZONABLES DEL ASEGURADO}

BALlesteros considera que la doctrina de las expectativas razonables del adherente es una mejor respuesta que las de las doctrinas contractualistas. Esta teoría aparece en los años 70, aplicándose, principalmente, a los litigios de seguros, pero luego se ha extendido a los demás contratos por adhesión y está en vías de admisión por el Uniform Contractual Code (UCC) norteamericano ${ }^{19}$.

Originada en los Estados Unidos20, viene teniendo mucha acogida en especial en el gran público y los consumidores, pero también en el empresariado, porque es un importante argumento para el asegurado al que se le rechaza un siniestro. Crea la posibilidad de revisar el contrato cuando la parte débil demuestra una inconsistencia entre lo que razonablemente podía esperarse de la póliza ${ }^{21}$.

\footnotetext{
18 Ballugera. Obra citada.

19 Ibidem

20 Un resumen de esta doctrina puede verse en De la MAZa GAZmuri, Íñigo. "Contratos por adhesión. Una mirada al caso estadounidense”. En: Revista Chilena de Derecho Privado 5 (2005), pp. 9-41.

21 Pinochet Olave, Ruperto. "La protección del contratante débil: doctrina de las expectativas razonables”. En: Gaceta Jurídica 297 (2005), pp. 18 ss., consultado en ReuTERs, Thomson cita on line: CL/ DOC/3549/2012. En particular, según este autor, esta doctrina es plenamente coincidente con las exigencias de la buena fe contractual, contempladas en el artículo 1546, "por lo que la aplicación en Chile de las expectativas razonables no requiere a priori, como pudiere pensarse, de una modificación legal, sino que, a nuestro entender, se necesita recurrir nada más que a la interpretación genuina de la norma”. Ídem. En jurisprudencia, aunque en el voto disidente, esta doctrina ha sido recientemente acogida a propósito de un fallo relativo a un "reconocimiento de deuda y compromiso de pago", en que los suscriptores asumieron
} 
Esta teoría considera insuficiente la firma del adherente, dejándose de lado la "parol evidence rule", entendiendo que el acuerdo contractual no se limita al condicionado general, sino que está sujeto a las expectativas razonables del adherente surgidas de los tratos previos, la publicidad y todas las demás circunstancias que intervienen en el contrato por adhesión. De ese modo las condiciones generales sólo se considerarán válidas en tanto que desarrollen los elementos mencionados o concreten el derecho dispositivo.

De esta manera esta doctrina es un procedimiento de control, ya que confluyen con ésta los resultados de la interpretación integradora y sistemática, pues el objeto que persigue no es excluir del contrato las cláusulas no consentidas, como se haría con las cláusulas abusivas, sino establecer el alcance del acuerdo a través de las expectativas razonables del adherente.

Esta doctrina nos lleva a la conclusión de que en caso de discrepancia entre expectativas razonables y el condicionado general, prevalecen las primeras, ya que mientras que las expectativas razonables forman parte del acuerdo contractual, las estipulaciones impresas en el formulario no tienen garantizada esa condición por la derogación de la "parol evidence rule".

Una crítica que se hace a la doctrina de las expectativas razonables es que se funda en el control del consentimiento de las condiciones generales, pero sobre la base de un adherente capaz de formarse expectativas sobre intrincados problemas jurídicos y sobre los detalles de cualquier contrato, sea típico o atípico. Empero, a mi propio entender, estas expectativas son o deberían ser entendidas en términos generales respecto de lo cubierto o no cubierto por una póliza en el caso de los seguros. Las aseguradoras y los corredores suelen ser muy buenos vendiendo y muy malos indemnizando cuando hay siniestros. Recién entonces aparecen las exclusiones y las limitaciones de cobertura que nunca se mencionaron cuando el cliente contrató la póliza. Se podría decir que cuando se vende una póliza de seguro esta tiene la apariencia de una hermosa mujer llena de promesas y buenos deseos, pero que a la ocurrencia de un siniestro aparece tal como es en realidad, una bruja que dice a todo no y que pone todos los peros posibles antes de decir que sí.

Por lo expuesto, la doctrina, en su dimensión de control del consentimiento insiste en la necesidad de que el predisponente informe al adherente, al margen de los requisitos de inclusión, de manera clara, sencilla y efectiva, de las estipulaciones que se aparten del derecho dispositivo o de las que supongan una novedad a fin de evitar sorpresas. En este aspecto la doctrina coincide con la de las cláusulas sorprendentes del derecho alemán. Si seguimos con el paralelo anterior la póliza debería ser vendida mostrando que es una bruja y no la bella mujer que nos venden actualmente.

que al suscribir dicho acuerdo su deuda sería eliminada de los registros comerciales de morosidad, cuestión que no era así y que el acreedor nunca tuvo intención de realizar. Vid. Corte Suprema, 21 de diciembre de 2017, Rol N 62173-2016, Un comentario a esta sentencia, haciendo hincapié en la pregunta ¿cómo han de establecerse las expectativas razonables?, puede verse en DE LA MAZA GAZMURI, Íñigo. "Información y expectativas razonables". En: El Mercurio Legal, viernes 05 de enero de 2018, disponible [en línea]: http://www.elmercurio.com/Legal/Noticias/Analisis-Juridico/2018/01/05/Informacion-y-expectativasrazonables.aspx (consultado 8 de junio de 2020). 
Los mayores problemas de la doctrina están en el control del contenido del contrato por adhesión. Respecto a la forma en que la doctrina excluye por nulas las cláusulas abusivas, algunos autores norteamericanos utilizan la doctrina de la incontestabilidad para dejar sin efecto las expectativas razonables. No obstante, BALLESTEROS, considera que esa expulsión es una función que compete también a las expectativas razonables del adherente, y esto sobre la base de la buena fe entendida como norma ética que impide al predisponente introducir en el contrato un clausulado desequilibrado ${ }^{22}$.

El hecho de que la doctrina expuesta provenga de una tradición jurídica diferente a la Derecho continental no debería ser obstáculo para incorporarla, más aún cuando el propio artículo 9 de la AGBG (Allgemeines Bürgerliches Gesetzbuch) responde a la doctrina de las expectativas razonables. Esta opinión, concuerda con las propuestas nacidas en el seno de la Unión Europea para construir puentes entre el Derecho continental, del que en el Perú somos herederos, y el "Common Law" con el objeto de caminar a la formulación de principios comunes ${ }^{23}$. Nuestra ley 29946 del contrato de seguro establece la buena fe como uno de sus principios rectores (artículo II a) y considero evidente que la doctrina de las expectativas razonables deviene de este principio que es central en el derecho contractual de seguros. Están además los artículos 168 y 1362 de nuestro Código civil que establece que los contratos deben negociarse (antes), celebrarse (durante) y ejecutarse (después) según las reglas de la buena fe.

Ejemplos de la incorporación mencionada en el párrafo anterior se encuentra en la Directiva 93/13/CEE sobre cláusulas abusivas, en su artículo 4.1, y en su correlato en el artículo 10 bis 1.IV, además del artículo 8 de la LGDCU (Ley general de defensa de los consumidores y usuarios) española, en cuanto se refiere a la integración del contrato por adhesión con el contenido de la publicidad, oferta y promoción de los productos y servicios. Nuestra LCS ha incorporado todo esto en sus artículos I, II a) y f), III, IV, Tercera, Octava, Novena, Décima, Decimoprimera y Decimosegunda, 28, 29, 31, 39, 40, 41, 50, 53, 69, 92, 93, 106, 118, 119, 122, 123, entre otros. Pero la norma europea que expresa mejor la doctrina de las expectativas razonables del adherente es el Decreto-lei portugués 446/85, de 25 de octubre, sobre "cláusulas contratuais generais" ${ }^{\prime 24}$, si bien deberían completarse con una regla que impusiese al predisponente la redacción del clausulado de modo claro, sencillo y concreto.

\section{BIBLIOGRAFÍA}

Anderson, Eugene R. \& Fournier, James J. Why Courts Enforce Insurance Policyholders' Objectively Reasonable Expectations of Insurance Coverage, 5 CONN. INS. LJ. 335,342-45 (1998).

\footnotetext{
22 Ibidem

23 Ballugera Gómez, Carlos. "Las expectativas racionales del adherente y los tratos preliminares a los 20 años de la ley de condiciones generales”. En: https://enlacancha.eu/2018/01/11/las-expectativas-racionalesdel-adherente-y-los-tratos-preliminares-a-los-20-anos-de-la-ley-de-condiciones-generales/. Consultado el $16 / 06 / 2020$

24 Ibidem
} 
Ballesteros Garrido, J. A. Las condiciones generales de los contratos y el principio de autonomía de la voluntad. José María Bosch Editor, Barcelona, 1999.

Ballugera Gómez, Carlos. "Las expectativas racionales del adherente y los tratos preliminares a los 20 años de la ley de condiciones generales". En: https://enlacancha. $\mathrm{eu} / 2018 / 01 / 11 /$ las-expectativas-racionales-del-adherente-y-los-tratos-preliminaresa-los-20-anos-de-la-ley-de-condiciones-generales/

De la Maza Gazmuri, Íñigo. "Contratos por adhesión. Una mirada al caso estadounidense". En: Revista Chilena de Derecho Privado 5 (2005), pp. 9-41.

Henderson, Roger C. The Doctrine of Reasonable Expectations in Insurance Law After Two Decades, 51 OHIO ST. LJ. 823,824 (1990).

Jaramillo, Carlos Ignacio y Kemelmajer de Carlucci, Aída. El criterio de razonabilidad. Editorial Ibáñez. Bogotá, 2020

Marano, Pierpaolo y Noussia, Kyriaki, editores. Transparency in Insurance Law. Springer. Cham, Suiza, 2019.

Pinochet Olave, Ruperto. "La protección del contratante débil: doctrina de las expectativas razonables”. En: Gaceta Jurídica 297 (2005).

RAHDERT, Mark C. Reasonable Expectations Revisited, 5 CONN. INS. L.J. 107, 108 (1998).

SchwaB, Klaus. ¿Qué tipo de capitalismo queremos?' publicado en Project Syndicate. The World's Opinión Page el 2 de diciembre de 2019. https://www.project-syndicate.org/ commentary/stakeholder-capitalism-new-metrics-by-klaus-schwab-2019-11/spanish

Stiglitz, Rubén. Contrato de seguros. La ley. Buenos Aires, 2004. 